\title{
Adult avoidant/restrictive food intake disorder: a case report
}

\author{
Transtorno alimentar evitativo/restritivo em uma adulta: \\ um relato de caso \\ Evelin Mascarenhas Soffritti \\ https://orcid.org/0000-0003-4288-437X \\ Bárbara Calmeto Lomar Passos ${ }^{2}$ \\ https://orcid.org/0000-0002-5574-2373 \\ Dharana Gaia Rodrigues 3 \\ https://orcid.org/0000-0002-3426-8801 \\ Silvia Regina de Freitas ${ }^{1}$ \\ https://orcid.org/0000-0003-1660-9278 \\ Bruno Palazzo Nazar ${ }^{4}$ \\ https://orcid.org/0000-0002-8325-1088
}

\section{ABSTRACT}

The aim this report is to present an adult case of avoidant/restrictive food intake disorder (ARFID) in a patient with atypical development. To emphasize the diagnostic and behavioral characteristics of this new nosological category included in the Feeding and Eating Disorders (FED) section of DSM-5. A woman with Down Syndrome in early adulthood who developed restriction and avoidance symptoms of food until the total eating refusal with weight loss,

\section{Keywords}

Eating disorders, feeding disorders, avoidant/ restrictive food intake disorder, Down syndrome, enteral feeding. malnutrition and dependence exclusively on enteral feeding by gastrostomy tube. This case exemplified how ARFID may remain a hidden diagnosis and even be misdiagnosed as other eating disorders, such as anorexia nervosa. The increase in diagnostic suspicion for this nosological entity with neurobiological/behavioral mechanisms involved in its clinical presentations in mind, might increase knowledge about this serious eating disorder, aiming the development of evidence-based interventions.

\section{RESUMO}

O objetivo deste relato é apresentar um caso de transtorno alimentar evitativo/restritivo (TARE) em uma paciente adulta com desenvolvimento atípico e salientar as características diagnósticas e comportamentais dessa nova categoria nosológica incluída na seção de Transtornos Alimentares da DSM-5. Mulher com síndrome de Down que, no início da vida adulta, evoluiu com sintomas de restrição e evitação alimentar até a recusa total da alimen-

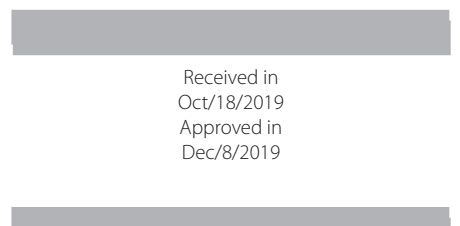

DOI: 10.1590/0047-2085000000253
1 Federal University of Rio de Janeiro (UFRJ), Institute of Psychiatry (IPUB), State Institute of Diabetes and Endocrinology (IEDE), Obesity and Eating Disorders Group (GOTA), Rio de Janeiro, RJ, Brazil.

2 Private Clinic, Rio de Janeiro, RJ, Brazil.

3 Federal University of Rio de Janeiro (UFRJ); Private Clinic, Rio de Janeiro, RJ, Brazil.

4 Federal University of Rio de Janeiro (UFRJ), Institute of Psychiatry (IPUB); Psychiatry and Mental Health Post Graduate Program (PROPSAM), Rio de Janeiro, RJ, Brazil. 


\section{Palavras-chave}

Transtornos alimentares, distúrbios alimentares, transtorno alimentar evitativo/restritivo, síndrome de Down, alimentação enteral. tação, com perda de peso, desnutrição e dependência total de alimentação enteral por gastrostomia. Este caso elucida como o diagnóstico de TARE pode permanecer oculto e ser confundindo com outras condições patológicas alimentares, como a anorexia nervosa. O aumento da suspeição diagnóstica para essa entidade nosológica, tendo em mente os mecanismos neurobiológicos/comportamentais envolvidos em suas apresentações clínicas, possibilitará o aumento do conhecimento sobre esse grave transtorno alimentar, visando ao desenvolvimento de intervenções eficazes baseadas em evidências.

\section{INTRODUCTION}

Avoidant/restrictive food intake disorder (ARFID) is described in the Feeding and Eating Disorders (FED) section of the diagnostic and statistical manual of mental disorders, 5th edition (DSM-5)1. ARFID was conceptualized from clinical syndromes not previously covered by categories in the DSM-IV and was classified as Feeding Disorder of Infancy and Early Childhood or Eating Disorder Not Otherwise Specified (EDNOS). Diagnostic criteria for ARFID are presented in table 1.

Despite ARFID being considered a pediatric disorder with an estimated prevalence of 3\%; one study found the same frequency among an adult community sample and another found $9.2 \%$ of individuals seeking treatment for FED, aged 15-40 years ${ }^{2}$. However, adult ARFID prevalence studies are lacking, probably because there aren't validated instruments to investigate this newly diagnostic category.

There are three domains to be assessed in ARFID, which represents motivation to eat, food related cognitions and food sensory perception. They present clinically as apparent disinterest either in eating or in food, concern about aversive consequences of eating, and avoidance based on food sensory characteristics. These symptoms may occur alone or in any combination, in any severity levels. The typical patient example in whom all three ARFID domains/presentations are present would be a young person with selective eating (sensory sensitivity) and chronic low general appetite (lack of interest in eating), who abruptly loses weight after a choking episode (for fear of aversive consequences) ${ }^{3}$.

A systematic search was performed using the descriptors ARFID in PubMed, Web of Science, Trip Medical Database, Google Scholar, SciELO and Lilacs. To our knowledge, this is the first ARFID report from Brazil. After searching the aforementioned databases on December 215t/2017, without any past time limit - until December/2017, using (ARFID OR Avoidant-Restrictive Food Intake Disorder), only 10 cases were found worldwide and their clinical features are presented in table 2 $^{4-11}$.

The aim of this report is to describe the case of an atypical development adult diagnosed with ARFID and highlight it's diagnostic characteristics in order to prompt awareness on how to better manage treatment of these individuals.
Table 1. ARFID diagnostic criteria 307.59 (F50.8)

\section{A. An eating or feeding disturbance (e.g., apparent lack of interest in eating or food; avoidance based on sensory characteristics of food; concern about aversive consequences of eating) as manifested by persistent failure to meet appropriate nutritional and/or energy needs associated with one (or more) of the following \\ 1. Significant weight loss (or failure to achieve expected weight gain or faltering growth in children). \\ 2. Significant nutritional deficiency. \\ 3. Dependence on enteral feeding or oral nutritional supplements. \\ 4. Marked interference with psychosocial functioning. \\ B. The disturbance is not better explained by lack of available food or by an associated culturally sanctioned practice.}

C. The eating disturbance does not occur exclusively during the course of anorexia nervosa or bulimia nervosa, and there is no evidence of a disturbance in the way in which one's body weight or shape is experienced.

D. The eating disturbance is not attributable to a concurrent medical condition or not better explained by another mental disorder. When the eating disturbance occurs in the context of another condition or disorder, the severity of the eating disturbance exceeds that routinely associated with the condition or disorder and warrants additional clinical attention.

Specify if:

In remission: After full criteria for avoidant/restrictive food intake disorder were previously met, the criteria have not been met for a sustained period of time.

Nota. American Psychiatric A. Dsm-5. In: Diagnostic and statistical manual of mental disorders, DSM-5. 2013. p. 334. Available from: http://displus.sk/DSM/subory/dsm5.pdf

\section{CASE PRESENTATION}

A 20-year-old female patient with Down Syndrome was referred by the liaison psychiatrist from a general hospital to a specialized eating disorders unit due to low weight, exclusive gastrostomy tube feeding and a possible diagnosis of anorexia nervosa (AN).

The patient presented a history of delayed psychomotor development, impairment of oral language development and intellectual disability (Wechsler Adult Intelligence Scale - WAIS-III in the 'extremely low' intelligence band - score IQ =63).

Previous to the patient's weight loss, her parents reported that her dietary pattern was marked by a "slowness" to eat and behavioural "rigidity". Also, she felt full after eating very little and was not interested on external food-related appetitive stimuli.

At the age of 18, the patient began to experience symptoms of coughing, choking, and a frequent behavior of spitting saliva, which developed to morning and, later, prandial nausea. She gradually went on to restrict the quantum of food. She started to avoid food based on texture 
(lumpy texture), which evolved to any solids. Eventually, she stopped swallowing any food or liquid. At the same time, she developed phobic symptoms about darkness and the sea, which coincided with raise in family stress.

The patient presented progressive weight loss for one year, starting at a normal BMI of $20.8 \mathrm{~kg} / \mathrm{m}^{2}$, according to the World Health Organization BMI categories, until she reached a very severely underweight BMI of $10.9 \mathrm{~kg} / \mathrm{m}^{2}$, which led her to be admitted at an inpatient general medical unit in a private hospital. Her diagnostic workup was inconclusive and after exclusion of all other clinical diagnoses, she was diagnosed with AN by a liaison psychiatrist. She was put on gastrostomy tube feeding associated with pharmacotherapy (fluoxetine 30 mg/day and quetiapine 50 mg/day) and her weight was slowly restored to and underweight BMI of 18,3 $\mathrm{kg} / \mathrm{m}^{2}$. However, even after discharge, she refused to resume oral feeding and maintained complete dependence on enteral nutrition.

Table 2. Summary of clinical cases

\begin{tabular}{|c|c|c|c|}
\hline Author, Year & Age/Sex & $\begin{array}{l}\text { Comorbities/Triggering } \\
\text { and family factors }\end{array}$ & $\begin{array}{c}\text { Clinical presentation and associated } \\
\text { aspects/BMI(adult) or estimated BMI } \\
\text { average } \% \text { (child) }\end{array}$ \\
\hline $\begin{array}{l}\text { Kreipe and } \\
\text { Palomaki, } \\
2012 .\end{array}$ & $\begin{array}{l}1.14 / \mathrm{M} \\
2.10 / \mathrm{F}\end{array}$ & $\begin{array}{l}\text { 1. Obsessive-compulsive traits not } \\
\text { related to food/Father with history of } \\
\text { picky eating. } \\
\text { 2. Choking episode as a trigger. }\end{array}$ & $\begin{array}{l}\text { 1. Sensory avoidance/Growth } \\
\text { failure/Psychosocial damage. } \\
\text { 2. BMl: uninformed. } \\
\text { 3. Aversive concern (fear of } \\
\text { choking)/weight loss. BMI: } \\
\text { uninformed. }\end{array}$ \\
\hline
\end{tabular}

Bryant- $\quad 13 / \mathrm{M} \quad$ Anxiety and low self-esteem/picky eater. Sensory avoidance/lack of interest in

Waugh,

2013.

Lopes et al., $\quad 32 / \mathrm{M}$

2014.

Hyperactivity, anxiety and hypochondriacal concerns/choking episode as a trigger of ARFID.

Chandranet $\quad 17 / \mathrm{M}$ al., 2015.

Lucarelliet $\quad$ 4/F al., 2017.

Autism spectrum disorder gastroesophageal reflux disease/milk and peanut allergies.

Aversive concern (fear of choking)/ weight loss/psychosocial trauma. BMI: $19,6 \mathrm{~kg} / \mathrm{m}^{2}$.

Sensory avoidance/nutritional deficiency (vitamin deficiencies $A$, D, E, K, B12 and folate)/psychosocial damage/aversive concern/weight loss/enteral feeding.

Initial BMI: $26,3 \mathrm{~kg} / \mathrm{m}^{2}$ Last BMI: $20,7 \mathrm{~kg} / \mathrm{m}^{2}$ (Loss of $20 \mathrm{~kg}$ in 2 months).

Sensory avoidance/psychosocial damage/oral supplements. BMI: Uninformed

Aversive concern (fear of painful bowel movements)/interest lack/ sensory avoidance (solid foods)/ weight loss/nutritional deficiency/ psychosocial damage/oral supplements/enteral feeding. Initial BMI: $23.5 \mathrm{~kg} / \mathrm{m}^{2}$. Last 5 years BMI: 12,5 kg/m².

$\begin{array}{ll}\text { Previous eating patterns } & \text { Treatment }\end{array}$

\section{Picky eater "since birth" (selectivity by smell, color and consistency of foods) and ritualized feeding/food neophobia. \\ 2. Uninformed.}

Lazy and picky eater (selectivity by color and taste of food) since early childhood/Food neophobia/delayed feeding when busy (playing on computer).

Uninformed.

Picky eater since five years/oral nutritional supplementations until 15year old/restricting fluid intake.

First 2 years old: persistent bottle refusal and the acceptance of few pureed foods/ from 2 to 4 years old: picky eating/supplement with soy milk.

Reduced appetite resulting from chronic undernourishment at least 5 years.

\section{Focused on guided imagery self-relaxation exercises prior to eating wanted foods/nutritional counseling/fluoxetine id. \\ 2. Biofeedback exercises to accept food.}

Cognitive behavioral therapy (CBT) focused in cognitive restructuring $(C R)$, anxiety management (AM), desensitization and unfamiliar food gradual exposure based therapy together with slow breathing and muscle relaxation techniques (BRT) combined with parental involvement/oral nutritional supplements (ONS).

Psychoeducation/CBT focused in CR, $A M$ and desensitization and food gradual exposure based therapy together with BRT/fluvoxamine 50 $\mathrm{mg}$ id and ethyl loflazepate $3 \mathrm{mg}$ id.

Hospitalization for clinical stabilization/vitamin replacement/ initial nasogastric enteral feeding/ combination of routine individual and family inpatient psychotherapy and quetiapine to manage anxiety/ therapeutic meal support/slow introduction of a varied oral diet/ outpatient rehabilitation with the following teams: endocrine, neurology, haematology, psychology, and the adolescent medical team.

CBT focused in systematic desensitization approach with rewards (discounted by parents).

Hospitalization for clinical stabilization/oral feedback (by refusal of enteral feeding)/ mirtazapine $7.5 \mathrm{mg}$ id/ rehospitalization with clinical complications in $\mathrm{CTI} /$ orogastric enteral feedings/transfer for psychiatric inpatient care. as a trigger of ARFID/anxiety and insomnia due pain and abnormal bowel function/several hospitalizations for severe malnourishment and weight loss. 


\begin{tabular}{|c|c|c|c|c|c|}
\hline Author, Year & Age/Sex & $\begin{array}{l}\text { Comorbities/Triggering } \\
\text { and family factors }\end{array}$ & $\begin{array}{l}\text { Clinical presentation and associated } \\
\text { aspects/BMI(adult) or estimated BMI } \\
\text { average \% (child) }\end{array}$ & Previous eating patterns & Treatment \\
\hline $\begin{array}{l}\text { Thomas et al., } \\
2017 .\end{array}$ & $11 / \mathrm{F}$ & $\begin{array}{l}\text { Chronic constipation/choking incident as } \\
\text { aggravation of ARFID. }\end{array}$ & $\begin{array}{l}\text { Acute food refusal (last } 14 \text { days): } \\
\text { aversive concern (fear of choking)/ } \\
\text { weight loss. } \\
\text { Chronic presentation: sensory } \\
\text { avoidance and interest lack/growth } \\
\text { failure/psychosocial damage/oral } \\
\text { supplements. } \\
\text { BMl: } 12.5 \mathrm{~kg} / \mathrm{m}^{2} \text { (<1st percentile). } \\
\text { Remained BMI < 1st percentile since } \\
\text { of } 6 \text { years old. }\end{array}$ & $\begin{array}{l}\text { Highly selective eater since } \\
\text { infancy (by food taste or texture } \\
\text { or if food were "mixed together" } \\
\text { in plate)/frequently required } \\
\text { coaxing from complete meals } \\
\text { (early satiety). }\end{array}$ & $\begin{array}{l}\text { Hospitalization for clinical } \\
\text { stabilization/mirtazapine/CBT } \\
\text { focused in feared foods gradual } \\
\text { exposure therapy (fear of choking)/ } \\
\text { family-based treatment (weight } \\
\text { and appetite increased)/repeated } \\
\text { exposure promotes acceptance of } \\
\text { new foods (food selectivity). }\end{array}$ \\
\hline $\begin{array}{l}\text { Paulette, } \\
2017 .\end{array}$ & $\begin{array}{l}1.13 / \mathrm{F} \\
2.17 / \mathrm{F}\end{array}$ & $\begin{array}{l}\text { 3. Constipation and nausea episodes as } \\
\text { trigger of ARFID/family anxiety. } \\
\text { 4. Vomiting and abdominal pain } \\
\text { episodes as trigger of ARFID/family } \\
\text { anxiety. }\end{array}$ & $\begin{array}{l}\text { 1. Aversive concern (fear of } \\
\text { gastrointestinal symptoms) } \\
\text { /weight loss. } \\
\text { Estimated BMI average \%: } 65.4 \% \text {. } \\
\text { 2. Aversive concern (fear of } \\
\text { gastrointestinal symptoms) } \\
\text { /weight loss. } \\
\text { Estimated BMI average } \%: 74.4 \% \text {. }\end{array}$ & $\begin{array}{l}1 \text { and 2: picky eating in } \\
\text { childhood. }\end{array}$ & $\begin{array}{l}1 \text { and 2: nasoenteric tube } \\
\text { feedback/CBT based on positive } \\
\text { reinforcement-reward for oral intake } \\
\text { and retention food/family therapy. }\end{array}$ \\
\hline
\end{tabular}

Nota. Interest lack: Presentation of ARFID with apparent lack of interest in eating or food. Sensory avoidance: Presentation of ARFID with avoidance based on sensory characteristics of food. Aversive concern: Presentation of ARFID with concern about aversive consequences of eating. Picky eating (selective eater): Inadequate dietary variety based on rejection of many "familiar" or "unfamiliar" foods. Food neophobia: Reluctance or avoidance to eat new foods. Family-based treatment: Treatment established for young patients with AN based at parent encouragement to take control of feedback and increasing supervision during meals and snacks.

After receiving assessments from the ED specialist team (endocrinologist, nutritionist, psychologist, speech therapist and psychiatrist), it was demonstrated that the patient met criteria for ARFID, since she presented food avoidance behavior, history of significant weight loss and dependence of tube feeding for nutritional replacement (criterion A); without report of food unavailability or cultural practice that explained the food restriction (criterion B). Moreover, she wasn't afflicted by a general medical condition that justified the either food refusal or the gastrostomy during hospital investigation (criterion D). Finally, a diagnosis of specific phobia for fear of choking or vomiting was discarded because there was an additional clinical impact of food behavior that made the diagnosis of ED more appropriate (criterion D). She didn't show any distress in relation to enteral caloric replacement, and neither distortion of body image, ruling out a diagnosis of AN (criterion C).

A therapeutic planning consisting of psychoeducation for both parents and patient; as well as cognitive behavioral psychotherapy focusing on social skills training, desensitization and gradual exposure to food and situational contexts involving feeding; participation in the food preparation process to increase interest in eating; and parent training to promote generalization to the domestic and social environment. Initially the patient touched food with her mouth even without swallowing and there was a progressive return of feeding through oral cavity over two years of treatment, masticatory and swallowing rehabilitation were instituted through speech therapist. After 6 months resuming swallowing, the patient was extubated and has maintained a normal BMl of $22 \mathrm{~kg} / \mathrm{m}^{2}$ after two years.

\section{DISCUSSION}

FED classification in diagnostic systems is still an evolving field. The DSM-IV presented the "Feeding Disorder of Infancy and Early Childhood" diagnosis within a category named "Disorders Usually First Diagnosed in Infancy, Childhood, or Adolescence", which allowed clinicians to classify patients who didn't meet criteria for other mental disorders with "persistent failure to eat adequately, as reflected in significant failure to gain weight or significant weight loss", and with onset of the disorder before age 6 years". The ARFID inclusion in the FED section of DSM-5 made it possible to establish this diagnosis even in adults.

Since more than half of children with FED didn't meet criteria into DSM-IV ED categories, a diagnostic classification was proposed by the Great Ormond Street Hospital ("Criteria GOS"). In addition to childhood onset AN and Bulimia Nervosa, they defined three other clinical presentations: "Food Avoidance Emotional Disorder", which classified prominent food avoidance associated with emotional conditions that impaired appetite; "Selective Feeding" in which a limited range of foods was set together with extreme reluctance to experiment new foods, leading to a significant impairment in social functioning; and the "Pervasive Refusal Syndrome" attributed to refusal to feed by a marked response to fear ${ }^{12}$. The "GOS criteria" presented significantly greater inter-rater reliability than ICD-10 and DSM-IV categories and the last three subtypes described contributed to define ARFID's DSM-5 criteria ${ }^{13}$.

The absence of some characteristic features of AN psychopathology are important in differential diagnosis. 
However, "non-fat-phobic AN" presentation'4 can be confused with ARFID. Individuals with this AN variant deny "fear of fatness", but sustain persistent behaviors to prevent weight gain despite low weight, such as "caloric-foods" avoidance, as well as oral supplements or even replacement enteral tube. Also, they might perform excessive physical exercise and/or induce vomiting after meals; and they fail to acknowledge the severity of their low weight'. The current report didn't present such behaviors and accepted tube feeding without questioning, making it possible to discard $\mathrm{AN}$ as the main diagnosis.

A neurobiological model proposed to support ARFID's pathophysiology involves lack of interest in food or eating as a feature associated with decreased activation of both the hypothalamic appetite-regulating centers and the primary taste cortex (anterior insula). Furthermore, food selectivity would be associated with oversensitivity in taste perception and food avoidance would result from a psychophysiological reaction to fear would be expressed by a hyperactivation of the brain region of the amygdala. It's postulated that individuals with multiple dysfunctional areas may be at increased risk of aggravation, persistence and relapse of ARFID³.

In seven ${ }^{4,5,7,7,10,11}$ out of the ten ARFID cases summarized in table 2, as well as in the current report, some eating patterns related to "undereating" are observed: picky eaters, slowness in eating, early satiety, ease of delaying feeding and emotional undereating ${ }^{15}$. These eating styles might reflect an impaired development of interest in food or eating, at varying degrees, that ultimately could point towards vulnerability in regulation of homeostatic appetite systems. In five $e^{4,7,10,11}$ of them, in addition to described case, gastrointestinal discomforts started and progressed alongside food avoidant responses conditioned to fear of aversive consequences, with aggravation of the clinical and psychosocial impairment, corroborating the refer neurobiological model. In nine ${ }^{4-11}$ cases and the present, one or more conditions associated with increased ARFID's risk were observed, such as: neurodevelopment disorders, anxiety or obsessive-compulsive traits/disorders, family anxiety and gastroesophageal reflux or gastrointestinal disturb?.

\section{CONCLUSION}

Clinicians should be aware of neurobiological/behavioral mechanisms involved in ARFID's different symptomatic domains. As in AN, ARFID clinical presentation may include low weight, malnutrition and significant psychosocial impairment due to food restriction/avoidance, but the avoidant behavior of caloric replacement and overvaluation of shape and weight are not observed. Inclusion of ARFID as a distinct diagnosis in DSM-5 rather than mixed into EDNOS category enables further research to elucidate knowledge gaps about ARFID in adults and across different developmental trajectories in order to improve care for these patients with effective evidence-based interventions.

\section{INDIVIDUAL CONTRIBUTIONS}

Evelin Mascarenhas Soffritti - Had substantially contributed to interpretation of data; had substantially contributed to drafting the article; and had given the final approval of the version to be published.

Bárbara Calmeto Lomar Passos - Had substantially contributed to analysis and interpretation of data; had substantially contributed to revising it critically for important intellectual content; and had given the final approval of the version to be published.

Dharana Gaia Rodrigues - Had substantially contributed to analysis and interpretation of data; had substantially contributed to revising it critically for important intellectual content; and had given the final approval of the version to be published.

Silvia Regina de Freitas - Had substantially contributed to analysis and interpretation of data; had substantially contributed to revising it critically for important intellectual content; and had given the final approval of the version to be published.

Bruno Palazzo Nazar - Had substantially contributed to conception and design and interpretation of data; had substantially contributed to revising it critically for important intellectual content; and had given the final approval of the version to be published.

\section{CONFLICTS OF INTEREST}

Evelin Mascarenhas Soffritti, Bárbara Calmeto Lomar Passos, Dharana Gaia Rodrigues, Silvia Regina Freitas don't state significant contributions and are not speakers and did not perform research to any pharmaceutical company. Bruno Palazzo Nazar has received a travel grant and has worked as a speaker to Shire pharmaceuticals.

\section{ACKNOWLEDGMENTS}

We thank Priscila Alves Medeiros de Sousa.

\section{REFERENCES}

1. American Psychiatric A. DSM-5. In: Diagnostic and Statistical Manual of Mental Disorders, DSM-5 [Internet]. 2013. p. 329-54. Available at: http://displus.sk/DSM/subory/dsm5.pdf. 
2. Zimmerman J, Fisher M. Avoidant/Restrictive Food Intake Disorder (ARFID). Curr Probl Pediatr Adolesc Health Care. 2017;47(4):95-103.

3. Thomas JJ, Lawson EA, Micali N, Misra M, Deckersbach T, Eddy KT. Avoidant/Restrictive Food Intake Disorder: a Three-Dimensional Model of Neurobiology with Implications for Etiology and Treatment. Curr Psychiatry Rep. 2017;19(8):54.

4. Kreipe RE, Palomaki A. Beyond picky eating: Avoidant/restrictive food intake disorder. Curr Psychiatry Rep. 2012;14(4):421-31.

5. Bryant-Waugh R. Avoidant restrictive food intake disorder: An illustrative case example. Int J Eat Disord. 2013;46(5):420-3.

6. Lopes R, Melo R, Curral R, Coelho R, Roma-Torres A. A case of choking phobia: Towards a conceptual approach. Eat Weight Disord. 2014;19(1):125-31.

7. Chandran JJ, Anderson G, Kennedy A, Kohn M, Clarke S. Subacute combined degeneration of the spinal cord in an adolescent male with avoidant/restrictive food intake disorder: A clinical case report. Int J Eat Disord. 2015;48(8):1176-9.

8. Lucarelli J, Pappas D, Welchons L, Augustyn M. Autism Spectrum Disorder and Avoidant/ Restrictive Food Intake Disorder. J Dev Behav Pediatr. 2017:38(1):79-80.
9. Tsai K, Singh D, Pinkhasov A. Pudendal nerve entrapment leading to avoidant/restrictive food intake disorder (ARFID): A case report. Int J Eat Disord. 2017;50(1):84-7.

10. Thomas JJ, Brigham KS, Sally ST, Hazen EP, Eddy KT. Case 18-2017 - An 11-Year-Old Girl with Difficulty Eating after a Choking Incident. N Engl J Med. 2017;376(24):2377-86.

11. Pitt PD, Middleman AB. A Focus on Behavior Management of Avoidant/Restrictive Food Intake Disorder (ARFID): A Case Series. Clin Pediatr [Internet]. 2017. Available at: http:// journals.sagepub.com/doi/10.1177/0009922817721158.

12. Bryant-Waugh R, Lask B. Annotation: Eating Disorders in Children. J Child Psychol Psychiatry [Internet]. 1995;36(2):191-202. Available at: http://doi.wiley. com/10.1111/j.1469-7610.1995.tb01820.x.

13. Nicholls D, Chater R, Lask B. Children into DSM don't go: a comparison of classification systems for eating disorders in childhood and early adolescence. Int J Eat Disord. 2000;28(3):317-24

14. Becker AE, Thomas JJ, Pike KM. Should non-fat-phobic anorexia nervosa be included in DSM-V? Int J Eat Disord. 2009:42(7):620-35.

15. Wardle J, Guthrie CA, Sanderson S, Rapoport L. Development of the Children's Eating Behaviour Questionnaire. J Child Psychol Psychiatry. 2001;42(7):963-70. 